\title{
University Choice: how attitudes frustrate girls' potential in STEMs
}

TINA RAMPINO

t.rampino@uq.edu.au

Institute for Social Science Research, The University of Queensland - Australian Research Council Centre of Excellence for Children and Families over the Life Course

There is wide consensus about the role played by girls' reluctance to engage with mathematics in secondary school their likelihood to obtain the higher than average salaries typically associated with science, technology, engineering, and mathematics (STEM) occupations in adulthood (Xie and Shauman, 2006). Girls, who outperform their male peers in reading abilities, lag behind in mathematics whose knowledge is fundamental to access specific higher education (HE) fields of study and well remunerated jobs. Most literature examining gender differences in post compulsory education field of study has focused on maths achievement and ignored scientific literacy where negligible gender differences have been found. How can we reconcile the lack 
of a scientific ability gender gap with the absence of women among the population of STEM graduates? Lot of this has to do with the way girls relate to science and the way they perceive their self-efficacy.

Our paper examines how students' and parents' attitudes to science shape girls' and boys' HE field of study choices taking into account maths and science ability, socio economic background and school level characteristics before students complete compulsory education. We want to understand why a 19-year-old boy and a 19-year-old girl who share similar family backgrounds and school environments, and have similar scientific and mathematics literacy levels at age 15 still make different choices in terms of their HE field of study. We aim to do so looking at their attitudes towards science measured at age 15 as well as at the role parental attitudes towards science can play. Since we do not observe parental attitudes directly we examine parental occupation. More specifically, we discern parental occupations into science and non-science related occupations and evaluate whether paternal and maternal occupation types affect 
girls and boys differently in their HE field of study. In addition to this, we investigate whether these factors can explain the likelihood of obtaining a STEM occupation at age 23.

The importance of STEM occupations to future prosperity is well recognised (Bell et al., 2014).

Increasing girls' participation in science addresses HE equity, and is an obvious way to increase labour supply for STEM occupations. By highlighting the role of attitudes our analysis identifies a clear mechanism that can be targeted to enhance girls' participation in non-traditional fields of education and eventually non-traditional occupations.

We use data from the Longitudinal Study of Australian Youth (LSAY) for the 2006 cohort (Y06). This is a 10-year cohort study administered by the Australian Department of Education, which collects detailed information primarily on respondents' education and labour market outcomes. The first wave of the survey is drawn from the pool of 15-year-old participants in the Programme for international Student Assessment (PISA) test. 


\section{Keywords}

Higher education, STEM, Gender, LSAY.

\section{Reference list}

Bell, J.M. et al. (2014) "Securing Australia's future: The role of science, research and technology in lifting Australian productivity", Australian Council of Learned Academies (ACOLA), Melbourne, VIC.

Xie, Y., Shauman, K.A., and Shauman, K.A. (2003) Women in science: Career processes and outcomes (Vol. 26, No. 73.4). Cambridge, MA: Harvard University Press. 